\title{
EXPERIMENTAL STUDY ON THE PLACEMENT OF THE ANGLE AND THE DISTANCE OF PARALLEL SKIMMING WALLS TO REDUCE INLET SEDIMENT IN A LATERAL INTAKE
}

\author{
Sadegh FARSHIDNIA ${ }^{1}$, Mojtaba SANEIE ${ }^{2 *}$, Hooman HAJIKANDI ${ }^{3}$, Mohammad ROSTAMI ${ }^{4}$
}

\begin{abstract}
Parallel skimming walls are regarded as one of the more efficient methods for controlling inlet sediment to a lateral intake. The present study attempts to experimentally scrutinize the impact of the angles of parallel skimming walls $(\theta)$, the corresponding distance (b), and the discharge variations of the main channel of the inlet sediment for the control of an intake. First, the impacts of parallel skimming walls incorporating three angles $\left(\theta=0^{\circ}, 15^{\circ}, 30^{\circ}\right)$, located in the front section of the intake and the distance between the walls $(b=10 \mathrm{~cm}, 20 \mathrm{~cm}, 30 \mathrm{~cm})$, were studied. A dimensional analysis showed the dimensionless extraction ratios and the relation between the variables in a laboratory. The results indicate that parallel skimming walls lead to average decreases of $69 \%, 41 \%$ and $26 \%$ in the amount of inlet sediment to the intake, for walls with angles of $0^{\circ}, 15^{\circ}$ and $30^{\circ}$, respectively. With regard to the distance between the walls, average decreases of $58 \%, 70 \%$ and $86 \%$ were observed for walls with placement distances of $b / H=2.5, b / H=5$ and $b /$

$H=7.5$, respectively.
\end{abstract}

Address

1 Sadegh Farshidnia - Ph.D. candidate, Department of Civil Engineering, Faculty of Engineering, Islamic Azad University, Tehran Central Branch, Tehran, Iran.

2 * Mojtaba Saneie - Associate Professor, Soil Conservation and Watershed Management Research Institute, (SCWMRI), Agricultural Research, Education and Extension, Organization (AREEO), Tehran, Iran.

3 Hooman Hajikandi - Assistant Professor, Department of Civil Engineering, Faculty of Engineering, Islamic Azad University, Tehran Central Branch, Tehran, Iran.

4 Mohammad Rostami Assistant Professor, Soil Conservation and Watershed Management Research Institute, (SCWMRI), Agricultural Research, Education and Extension, Organization (AREEO), Tehran, Iran.

* Corresponding author: Saneie_m@scwmri.ac.ir

\section{Key words}

- Lateral Intake

- River Engineering,

- Sediment Control,

- Skimming Walls.

\section{INTRODUCTION}

With regard to the importance of rivers as key water resources, the intake and branching of their flow are considered as one of the most important topics of the hydraulic engineering discipline. Gravity intakes are known as the oldest river harvesting systems that have various applications. The deviation of water by a lateral intake leads to problems, such as the entry of sediment into channels and water transmissions systems. As the flow approaches the intake, due to the flow separation towards the lateral channel, the stream is accelerated in a transverse direction and is divided into two portions in such a way that one portion will enter the intake, while the other portion flows into the main channel downstream (Hashid et al., 2015; Herrero et al., 2015; Neary \& Odgaard, 1993).

The accumulation and entry of sediments into the intake span is known as the most common problem of these systems. The lack of control over inlet sediment into intakes leads to the transportation of these materials into irrigation channels and facilities, thereby causing the emergence of numerous issues due to the settlement of sediment in various zones. A parallel skimming wall structure located in the main channel at the intake channel span is a desirable solution for preventing the entry of sediment volume into lateral intakes. This structure consists of two plates; one of these plates has an angle obliquely attached to the shore, while the other plate continues parallel to the direction of the main stream.

For Barkdoll et al. (1999), the second plate can rotate around a $\theta$ angle. This structure causes the development of rotations downstream, the extension of which exerts a transverse shear stress on the river bed (i.e., an area with a maximum sediment concentration). The vortices that develop at the low edge of the wall not only rotate, but also are transferred to the downstream and lead to the formation of bigger vortices. The vortex is formed close to the head of the ending 
edge. These vortices are converted into a spiral movement and lead to variations in the bed shear stress and the bottom topography of the river (Odgaard and Wang, 1991).

Finally, by making a relatively continuous deep groove (slot) along the main channel in front of the intake span, the sediments are transported downstream; as a result, the amount of inlet sediment into the lateral intake is reduced.

Khanjani et al. (1999) investigated the role of submerged vanes in controlling the sediment in an intake span. They attempted to achieve the array and dimensions of a submerged vane system for maximizing the flow depth in front of the intake. According to this method, the longitudinal distance between the plate row, the crossing angle of the flow with plates, the transverse distance between the plates, the plate heights (altitudes), and the ratio of the plates' altitudes to the plates' lengths were taken into account as the variables, and the results were compared with the estimations of Odgaard and Wang (1991).

The results indicated that it is important to optimize the array and dimensions of the submerged vane system in front of the intake span to prevent the effect of sediments on the intake span by specifying the flow and sediment parameters. Afterwards, the optimized parameters are employed to design the submerged vane system to achieve the most desirable results; i.e., maximizing the depth of the flow located in front of the intake span. Younesi et al. (2005) experimentally studied the impact of the performance of the longitudinal array of the submerged plates within a direct channel on the topography, the increase in the intake's efficiency, and a reduction in sedimentation within the span of the gravity intake.

With regard to the results, it was concluded that the regular array of submerged vanes with a longitudinal space of $4 \mathrm{H}$ is more appropriate, compared to plates with $3 \mathrm{H}$ and $6 \mathrm{H}$ at a distance $(\mathrm{H}$ denotes the plate's height). Hassanpour (2007) studied the effects of compound submerged plates on the control of the sediment entry into the lateral intake with an intake angle of. The hybrid submerged plates are developed by combining the submerged plates of the surface of the flow with the bottom submerged plates. The experiments were accomplished in a flume with a length of $17 \mathrm{~m}$ and a width of $1 \mathrm{~m}$ with a horizontal intake channel of $2.53 \mathrm{~m}$ in length, $40 \mathrm{~cm}$ in width, and an intake angle of $90^{\circ}$.

They also studied the inlet sediment control to the intake span for various discharges and ratios in the use of the bottom submerged plates in a regular array via the submerged compound plates with three different surface vane heights. The results ascertained that among the various alternatives for the submerged compound plates, the submerged compound plates incorporating a surface vane height of 0.5 as the characteristic parameter exhibited a better performance in controlling the entry of the sediment into the intake. In fact, this option prevents the entry of sediment into the intake span for an intake ratio of $8 \%$, while for an intake ratio of $16 \%$, it outperforms the alternative solutions.

Rezabandloo (2017) focused on the application of a skimming wall structure for controlling the sediment entering the intake. In that study, the simultaneous use of two structures, namely, the skimming wall and spillway for decreasing the entry of sediment into the lateral intake, was studied. The authors experimentally studied the impact of the angle of the skimming wall with the shore, a combination of the skimming wall and spillway, the effect of the discharge variations of the main channel on the entry of the sediment into the intake, and the ratio of the intake and the bed's topography. The experiments were conducted for four discharges of $30 \mathrm{l} / \mathrm{s}, 40 \mathrm{l} / \mathrm{s}, 50 \mathrm{l} / \mathrm{s}, 60 \mathrm{l} / \mathrm{s}$. The placement angles of $10^{\circ}, 14^{\circ}$ and $18^{\circ}$ relative to the adjacent shore were assumed for the skimming wall. When performing the dimensional analysis, the dimensionless ratios of the extraction and the experiment's variables were determined. The results indicated that the presence of a skimming wall and its combination with a spillway lead to an average reduction of $77 \%$ and $74 \%$ in the entry of the sediment into the intake for angles of $10^{\circ}, 14^{\circ}$ and $18^{\circ}$, respectively.

Barkdoll et al. (1995) investigated the efficiency of submerged vanes for preventing the accumulation of sediment within the intake span. They concluded that the use of submerged plates along the intake span can prevent almost $70 \%$ to $80 \%$ of the entry of the sediment into the intake. The cross angle of the vanes (plates) and upstream can lead to excessive scouring in the base of the submerged vanes, which is followed by the overturning of the submerged plates. For a higher velocity, the vanes exhibit a better performance in preventing the entry of the sediment into the intake. The common form of scouring can be changed close to the main channel wall in a downstream intake, and the deployment of submerged vanes leads to variations in the sedimentation adjacent to the intake. Ramamurthy et al. (2007) demonstrated that the length and width of the separation zone of the flow for the intake channel is reduced, due to an increase in the ratio of the diversion of the flow. Moreover, the scope of the separation zone in the intake channel at the bottom is less than that of the separation zone at the surface. Ghohari et al. (2009) examined the sediment control in an intake by employing the submerged vanes and a spillway. They inferred that the efficiency of the vanes is increased by constructing the spillway on the front side of the intake and that the amount of the entry of the sediment into the intake is decreased.

Salemnia and Shafaei-Bajestan (2011) studied the impact of the intake ratio on the amount of sediment within the inlet bed of the intake for a trapezoidal channel $(\mathrm{z}=1.5)$ with an intake angle of , relative to the flow direction with and without the submerged vanes. The results showed that any increase in the intake ratio from $7.5 \%$ to $16 \%$ leads to an average increase in the volume of the entry of the sediment into the intake up to $23 \%$, for both cases with and without the utilization of the submerged vanes. Atarzadeh et al. (2014) conducted an experimental study on the impact of a sill, spillway, and submerged vanes on the control of the sediment and the bed topography for intake discharge ratios of $0.12,0.15$ and 0.18 for lateral intakes. They concluded that a spillway plays an important role in controlling the sediment, compared to other alternatives.

The combined use of a spillway and sill leads to a $90 \%$ reduction in the amount of sediment deviated toward the intake, compared to the use of a sill alone. Jafari-Mianaei and Ayyoubzadeh (2014), conducted an experimental survey regarding the impact of the slope of the wall of the main channel on the amount of the entry of the sediment into the lateral intake with and without using submerged vanes; they found that the use of submerged vanes for both cases, namely the vertical wall and the sloping wall of the main channel, leads to a mitigation in the amount of the entry of sediment entry into the intake. However, such a reduction for a sloping wall, particularly for a low intake ratio, is greater than that of a vertical wall and that in the case of deploying submerged vanes for a sloping wall with a diverted discharge rate of $12 \%$, up to a $100 \%$ reduction can be observed in the amount of inlet sediment to the intake channel.

Abbasi and Nejad-yazdi (2014) reported that the utilization of a sill and submerged vanes leads to a decrease in the amount of the entry of sediment into the intake up to $72 \%$ relative to the mere deployment of a sill and up to $45 \%$ relative to the mere deployment of submerged vanes. Moradinejad et al. (2017) experimentally studied the flow patterns and sediment control using a skimming wall and spillway at the input section of the lateral intake.

They conducted an analysis for two experimental groups. The first experimental group aimed at determining the impact of the placement and angle of both the spillway and skimming wall, while the second experiment attempted to investigate the impact of the skimming wall's angle in combination with the spillway on the deviation of the flow and sediment for the lateral intake. The results demonstrated that when a skimming wall is coupled with a spillway, it is possible to observe an average $81 \%, 78 \%$ and $76 \%$ reduction in the 


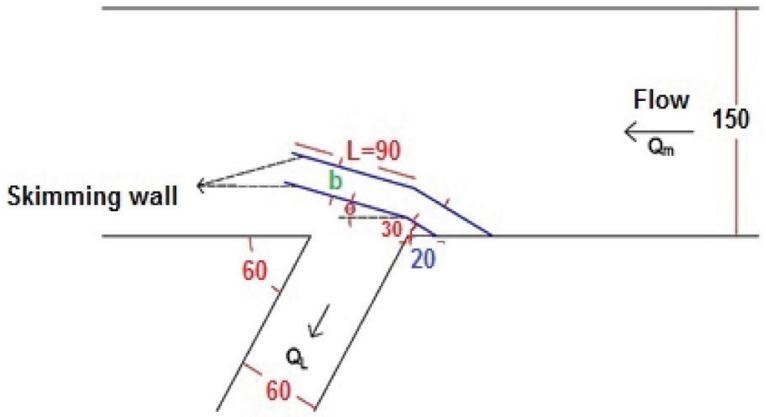

Units in $\mathrm{Cm}$

Fig. 1 General schematics of the experimental flume and placement of parallel skimming walls

inlet sediment for a wall with angles of $10^{\circ}, 14^{\circ}$ and $18^{\circ}$, respectively. Tabrizi et al. (2017) assessed the impact of a spillway's structure on the modification of a deviated flow pattern to the intakes located at an arc. The results verified that the sediment deviation ratio is highly influenced by the intake ratio and that any increase in this ratio may lead to a severe increase in the deviation ratio. The presence of the spillway structure upstream of the intake along with applying the modification on the flow pattern around the intake leads to a reduction in the sediment deviation rate.

Moreover, Nakato et al. (1990) focused on an array and angle of submerged vanes, while Barkdoll et al. (1997) studied the combination of submerged vanes with a skimming wall. In addition, Nakato and Odgen (1998) investigated the array of submerged vanes and their combination with a sill, while Barkdoll et al. (1999) analyzed an array of submerged vanes, the combination of these vanes with a skimming wall, and a modification of the intake span. With regard to the available literature, it is obvious that the preceding studies are mostly concerned with studying the submerged vanes, sill, and spillway or a combination of these structures. Hence, further studies and research with a focus on implementing parallel skimming walls in front of the intake are required.

In addition, it is essential to use two parallel skimming walls and make a comparison between cases with and without this system in order to study the impact of a skimming wall's angle () and the associated distance () between the walls on the amount of the entry of sediment into an intake. For this purpose, the present study uses two parallel skimming walls to study the possible impact on inlet sediment control to the lateral intake with an angle of for a rectangular channel. Fig. 1 shows the schematics of the structure.

\section{MATERIALS AND METHODS}

Due to the high number of effective parameters for the entry of bed load sediment into an intake span, dimensionless figures have been assumed in order to make the parameters dimensionless and to determine the experimental procedure. Using the dimensional analysis of Buckingham's method, which considers the effective parameters on the phenomena, a series of a dimensionless group was developed, and the dimensionless relations were obtained by accomplishing the calculations. Numerous parameters have an impact on the entry of the inlet sediment stream into the intake, which are as follows:

$Q_{m}$ represents the flow discharge for the main channel; $Q_{l}$ is the flow discharge in the intake channel; $D$ refers to the depth of the flow for the main channel; $U_{m}$ denotes the velocity of the flow in the main channel; $\mathrm{U}_{\mathrm{L}}$ denotes the velocity of flow for the intake channel; $B_{m}$ represents the width of the main channel; $S_{m}$ is the width of the intake channel; represents the slope (gradient) of the main channel; $g$ is the gravitational acceleration; $\rho$ is the density of the flow; $v$ denotes the kinematic viscosity; $\gamma$ is the angle of the intake channel with the main channel; $\beta$ is the angle of the skimming wall with the shore; $H$ represents the height of the skimming wall plates; $L_{0}$ refers to the length of the initial (primary) branch of the skimming wall; while $L$ refers to the length of the secondary branch of the skimming wall. T represents the duration of the experiment; $d_{50}$ denotes the mean diameter of the sediments; is the density of the sediment; $K_{s}$ denotes the toughness of the bed; $b$ refers to the distance of the walls; $\theta$ is the angle of the skimming wall's secondary branch with a horizontal axis, and $V$ is the volume of the inlet sediment to the intake.

As the parameters, including $\gamma, B_{L}, B_{m}, \beta, d_{50}, \rho_{s}, \rho, t, v, S_{m}, K_{s}, L_{0}$, $\mathrm{L}$ and $\mathrm{H}$ are constant, the effective parameters of the phenomena were identified, and the dimensionless ratios were specified.

Based on Buckingham's method and the elimination of constant dimensionless parameters, the final dimensionless relation was obtained by applying algebraic operations on the dimensionless ratios:

$$
R M S E=\left[\frac{1}{n} \sum_{i=1}^{n}\left(y_{c a l}-y_{o b s}\right)^{2}\right]^{0.5}
$$

$Q_{R}=\frac{Q_{l}}{Q_{m}}$ refers to the discharge ratio of the intake channel to the discharge of the main channel (intake ratio); Fr denotes the Froude number of the upstream of the intake; $\left(\frac{V}{D^{3}}\right)$ represents the volume of the inlet sediment to the intake with a stream depth to a power of 3 ; $\frac{b}{H}$ is the distance between the skimming walls with a wall height out ${ }_{\text {of }}^{H}$ the bed; and $\theta$ denotes the angle of the secondary branch of the skimming wall with a horizontal axis.

The associated experiments were accomplished at the Soil Conservation and Watershed Management Research Institute (SCRI) of Tehran in a flume $12 \mathrm{~m}$ in length, $1.5 \mathrm{~m}$ in width, and $0.9 \mathrm{~m}$ in height and incorporating a water circulation system. The intake was realized through a lateral channel with a width, length, and angle of $0.6 \mathrm{~m}$, $2.5 \mathrm{~m}$ and $60^{\circ}$, respectively, relative to the direction of the stream within the main channel. The main channel with a gradient/slope of 0.002 and a horizontal intake, were aligned with the sedimentary bed of the main channel. The intake channel was located at a distance of $9 \mathrm{~m}$ from an upstream stilling pool and a distance of $3 \mathrm{~m}$ from the adjustment valve/gate of the surface water within the end section of the flume. A closed water circulation system was used for the flume, which provides the required water from the linked ground storages embedded beneath the flume. The inlet discharge is controlled at the pumping station using adjustable control valves. The stream depth is adjusted via valves located at the end of each main channel and intake. For measuring the flow of the main and intake channels, sharpedged rectangular and triangular overflows were adopted, while for measuring the water depth, a point gauge was used.

The parallel skimming walls consisted of two branches in such a way that the oblique branches were adhered to the wall of the main channel, with lengths of $30 \mathrm{~cm}$ and $70 \mathrm{~cm}$, and an out-bed height of 4 $\mathrm{cm}$, whose one side was attached to the coast side of the intake with an angle of , while the other side was attached to the second branch of the skimming wall. The second branch of the skimming wall with a length (L) of $90 \mathrm{~cm}$ and an out-bed height of $4 \mathrm{~cm}$ forms an angle of with the direction of the main stream. Figs. 2 presents a view of the flume used in the experiments and the location of the placement of the parallel skimming walls.

The sedimentation used in the present experiments was selected in such a way that it does not undergo suspensions and moves as a bed load. Therefore, sand with an average diameter of $1 \mathrm{~mm}$, a specific density of $2.65 \mathrm{~g} / \mathrm{cm}^{3}$, a standard deviation of 1.47 , and a uniformity coefficient $\mathrm{Cu}$ of 2.2 was utilized.

With regard to the shield parameters and the Reynolds of the computational boundary for the aforementioned conditions and 


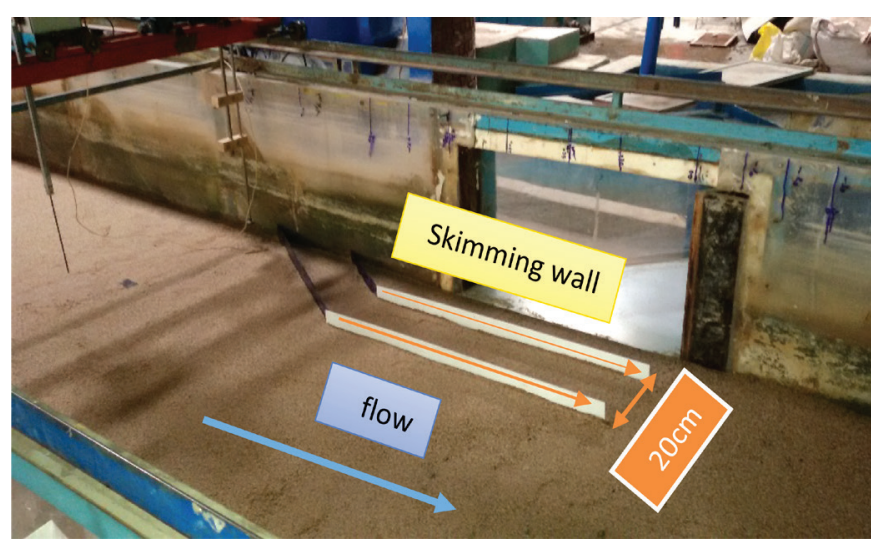

Fig. 2 View of the parallel skimming walls installed in front of the intake span with an angle of $0^{\circ}$ and a distance of $20 \mathrm{~cm}$

shield curves, the parameter of the shields is greater than the critical shield parameter, and the bed sediment motion can be observed for a discharge of $25 \mathrm{l} / \mathrm{s}$ or greater values.

The experiments and tests were performed to assess the impact of the angle of the skimming wall's second branch $(\theta)$ and the distance of the placement of the two skimming walls from each other (b) on the entry of the sediment into the intake. Angles with values of $\theta=0^{\circ}$, $15^{\circ}$ and $30^{\circ}$ relative to the direction of the flow within the main channel were assumed. Moreover, it was assumed that the skimming walls are placed from each other with distances of $10 \mathrm{~cm}, 20 \mathrm{~cm}$ and $30 \mathrm{~cm}$. For each placement, experiments with discharge values of $30 \mathrm{l} / \mathrm{s}, 40$ 1/s , 50 1/s , 60 l/s were performed. After each experiment, the volume of the entry of sediments into the intake (V) was measured. Tab. 1 presents information about the experiment and the range of variations for each variable.

Tab. 1 Variable values for experiments

\begin{tabular}{|c|c|c|c|c|c|c|c|}
\hline Parameters & $\begin{array}{c}Q_{m} \\
(l / s)\end{array}$ & $\begin{array}{c}Q_{L} \\
(l / s)\end{array}$ & $\begin{array}{c}D \\
(\mathrm{~cm})\end{array}$ & $\boldsymbol{F r}$ & $Q_{R}$ & $b(\mathrm{~cm})$ & $\Theta\left({ }^{\circ}\right)$ \\
\hline \multirow{3}{*}{ Case \#1 } & \multirow{3}{*}{30} & \multirow{3}{*}{4.8} & \multirow{3}{*}{7.7} & \multirow{3}{*}{0.30} & \multirow{3}{*}{0.16} & 10 & $\mathbf{0}$ \\
\hline & & & & & & 20 & 15 \\
\hline & & & & & & 30 & 30 \\
\hline \multirow{3}{*}{ Case \#2 } & \multirow{3}{*}{40} & \multirow{3}{*}{11.2} & \multirow{3}{*}{8.1} & \multirow{3}{*}{0.37} & \multirow{3}{*}{0.28} & 10 & $\mathbf{0}$ \\
\hline & & & & & & 20 & 15 \\
\hline & & & & & & 30 & 30 \\
\hline \multirow{3}{*}{ Case \#3 } & \multirow{3}{*}{50} & \multirow{3}{*}{17.5} & \multirow{3}{*}{8.2} & \multirow{3}{*}{0.45} & \multirow{3}{*}{0.35} & 10 & $\mathbf{0}$ \\
\hline & & & & & & 20 & 15 \\
\hline & & & & & & 30 & 30 \\
\hline \multirow{3}{*}{ Case \#4 } & \multirow{3}{*}{60} & \multirow{3}{*}{25.8} & \multirow{3}{*}{8} & \multirow{3}{*}{0.56} & \multirow{3}{*}{0.43} & 10 & 0 \\
\hline & & & & & & 20 & 15 \\
\hline & & & & & & 30 & 30 \\
\hline
\end{tabular}

\section{RESULTS}

The coefficient of determination $\left(\mathrm{R}^{2}\right)$ and the Root Mean Square Error (RMSE) were used for validating the relations. $\mathrm{R}^{2}$ denotes the statistical measurement of the closeness of the data to the fitted regression lines.

$\mathrm{R}^{2}$ is defined as the square of the correlation coefficient between $\mathrm{y}$ and $\hat{y}$ (i.e., the second order of the correlation coefficient between

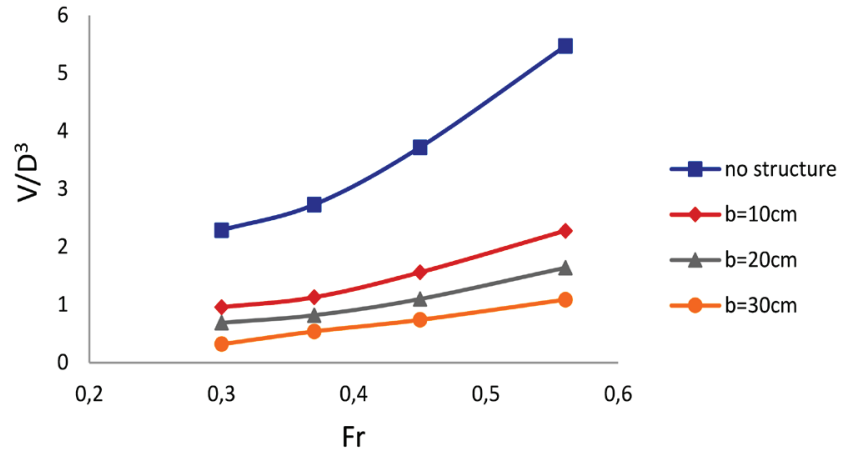

Fig. 3 Variation in with the Fr for various distances of the skimming walls from each other

the actual values of the depended variable and the values estimated by the model):

$$
R^{2}=\frac{\sum\left(y_{i}-\hat{y}_{i}\right)^{2}}{\sum\left(y_{i}-\bar{y}\right)^{2}}
$$

Where $y_{i}$ refers to the observational value, denotes the computational value, and represents the mean value.

The mathematic declaration of the RMSE index is as below:

$$
R M S E=\left[\frac{1}{n} \sum_{i=1}^{n}\left(y_{c a l}-y_{o b s}\right)^{2}\right]^{0.5}
$$

$y_{c a l}$ and $y_{o b s}$ refer to the calculated and observed values, respectively, for the variables of the validated data. $\mathrm{N}$ denotes the amount of available data. The low and near-zero value for the aforementioned index is highly desirable.

\subsection{Variations in the deviated sediment volume ratio $\left(\frac{V}{D^{3}}\right)()$ with changes in the Froude number $(\mathrm{Fr})$ for skimming walls with different distances}

In this section, the pattern and impressionability of $\frac{V}{D^{3}}$ due to the various distances of the skimming walls and Froude numbers are studied, and the associated relation with the Froude number of the main channel for various distances is expressed. For this purpose, relation with the Fr for distances, including $b=10 \mathrm{~cm}, b=20 \mathrm{~cm}$ and $\mathrm{b}=30 \mathrm{~cm}$ is analyzed, assuming a constant length for the skimming walls $(\mathrm{L}=90 \mathrm{~cm})$, a constant angle for the second branch of the skimming walls (), and a constant height for skimming walls $(\mathrm{H}=4 \mathrm{~cm})$. Fig. 3 and Tab. 2 present the associated results.

\begin{tabular}{|c|c|c|c|c|}
\hline Row & $\begin{array}{c}\text { Distance of skimming } \\
\text { walls (cm) }\end{array}$ & Relation & $\boldsymbol{R}^{2}$ & RMSE \\
\hline 1 & No structure & $\frac{V}{D^{3}}=11.89 F r^{1.41}$ & 0.97 & 0.0009 \\
\hline 2 & 10 & $\frac{V}{D^{3}}=4.95 F r^{1.41}$ & 0.97 & 0.1472 \\
\hline 3 & 20 & $\frac{V}{D^{3}}=3.51 F r^{1.39}$ & 0.97 & 0.0574 \\
\hline 4 & 30 & $\frac{V}{D^{3}}=3.43 F r^{1.93}$ & 0.99 & 0.0252 \\
\hline
\end{tabular}

With regard to the results of the analysis presented by Fig. 3 and Tab. 2, it can be concluded that:

1) For a constant distance, any increase in the Froude number leads to an increase in $\frac{V}{D^{3}}$. That is, there is a directional relation between $\frac{V}{D^{3}}$ and the Froude number.

2) For a constant Froude number, an increase in the distances of the walls from each other leads to a reduction in $\frac{V}{D^{3}}$. 


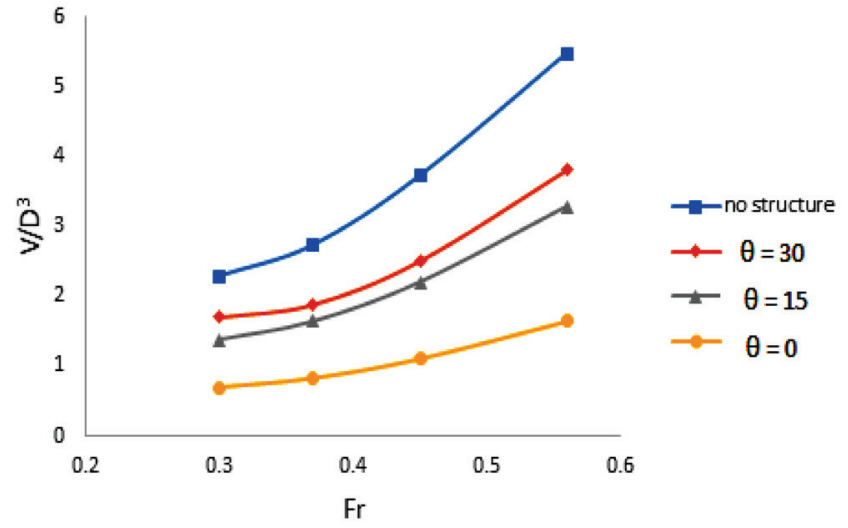

$\mathbf{r i g}+\mathbf{4}$ varlations in witn ine rr jor aljerent angıes of the secona branch of the skimming walls towards direction of the main stream

\subsection{Variations in the deviated sediment volume ratio $\mathrm{V} / \mathrm{D}^{3}$ with changes in the Froude number $(\mathrm{Fr})$ for different angles of the skimming walls}

In this section, the pattern and impressionability of due to the various angles of the skimming walls and the Froude number are studied, and the associated relation with the Froude number for different angles is declared. For this purpose, the relation with the Fr for the angles, including $\theta=0^{\circ}, \theta=15^{\circ}$ and $\theta=30$ is scrutinized, assuming a constant length for the skimming walls $(\mathrm{L}=90 \mathrm{~cm})$, constant distance for skimming walls from each other $(\mathrm{b}=20 \mathrm{~cm})$, and a constant height for the skimming walls $(\mathrm{H}=4 \mathrm{~cm})$. Fig. 4 and Tab. 3 present the results.

With regard to the analysis of the results (Fig. 4 and Tab. 3), it can be concluded that:

1) For a constant angle, an increase in the Froude number leads to an increase in $\frac{V}{D^{3}}$, i.e., there is a direct relation between $\frac{V}{D^{3}}$ and the Froude number.

2) For a constant Froude number, an increase in the angle of the second branch of the wall, relative to the direction of the flow of the main channel, leads to an increase in $\frac{V}{D^{3}}$.

\subsection{Variations in the deviated sediment volume ratio $\left(V / D^{3}\right)$ with distances in the height of the skimming walls of $b / H$ in for different Froude numbers}

The present section is dedicated to a study of the pattern and impressionability of $\frac{V}{D^{3}}$ due to the distance between the two skimming $\underset{V}{\text { walls }}$ from each other with a height of $\frac{b}{H}$ and the Froude number. The $\frac{V}{D^{3}}$ associated relation with $\frac{b}{H}$ for the Froude number is expressed. The $\frac{V}{D^{3}}$ relation with $\frac{b}{H}$ for the Froude numbers, including $0.30,0.37,0.45$ and 0.56 is studied, assuming a constant length for the skimming walls $(\mathrm{L}=90 \mathrm{~cm})$, and the angle of the second branch for the skimming walls $(\theta=0)$. Tab. 4 and Fig. 5 present the results.

Based on the analysis of the results (Fig. 5 and Tab. 4), it can be concluded that:

1) For a constant Froude number, an increase in $\frac{b}{H}$ leads to a re$\underset{V}{\text { duction in }} \frac{V}{D^{3}}$, implying that there is a reverse relation between $\frac{V}{D^{3}}$ and $\frac{b}{H}$.

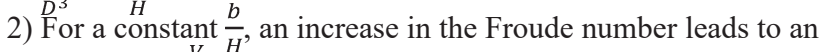
increase in $\frac{V}{D^{3}}$.
Tab. 3 Statistical information of with the Fr for different angles of the second branch of skimming walls towards the direction of the main stream direction

\begin{tabular}{|c|c|c|c|c|}
\hline Row & Angle $(\boldsymbol{\theta})$ & Relation & $\boldsymbol{R}^{2}$ & RMSE \\
\hline 1 & No structure & $\frac{V}{D^{3}}=11.89 F r^{1.41}$ & 0.97 & 0.0009 \\
\hline 2 & 0 & $\frac{V}{D^{3}}=3.51 F r^{1.39}$ & 0.97 & 0.0574 \\
\hline 3 & 15 & $\frac{V}{D^{3}}=7.02 F r^{1.39}$ & 0.97 & 0.1149 \\
\hline 4 & 30 & $\frac{V}{D^{3}}=7.55 F r^{1.31}$ & 0.94 & 0.1899 \\
\hline
\end{tabular}

Tab. 4 Statistical information on the $\frac{V}{D^{3}}$ relation with $\frac{b}{H}$ for different Froude numbers

\begin{tabular}{|c|c|c|c|c|}
\hline Row & Froude Number (Fr) & relation & $\boldsymbol{R}^{2}$ & RMSE \\
\hline 1 & 0.30 & $\frac{V}{D^{3}}=-0.128 \frac{b}{H}+1.297$ & 0.99 & 0.0235 \\
\hline 2 & 0.37 & $\frac{V}{D^{3}}=-0.118 \frac{b}{H}+1.420$ & 0.99 & 0.0071 \\
\hline 3 & 0.45 & $\frac{V}{D^{3}}=-0.164 \frac{b}{H}+1.953$ & 0.99 & 0.0236 \\
\hline 4 & 0.56 & $\frac{V}{D^{3}}=-0.238 \frac{b}{H}+2.860$ & 0.99 & 0.0212 \\
\hline
\end{tabular}

\section{DISCUSSION}

To make a comparison between the results of the present study and comparable works, the results and findings of Barkdoll et al. (1999), Raudkivi (1993), Hassanpour (2007), and Moradinejad et al. (2017) were studied. Fig. 6 illustrates the relation between the intake ratio $\left(Q_{R}\right)$ and the ratio of the deviated sediment to the intake $\left(G_{R}\right)$ in the absence of a sediment control structure. The results obtained by previous studies ascertained that an increase in the intake ratio $\left(Q_{R}\right)$ leads to an increase in the deviated sediment ratio $\left(G_{R}\right)$ to the intake.

In the results obtained by Barkdoll et al. (1999), a turning point exists in such a way that any increase in the intake ratio leads to a reduction in the ratio of the deviated sediment to the intake. According to the experiments conducted by Raudkivi (1993) on an intake with an angle of , there are turning points after which any increase in the intake ratio leads to a lower reduction in the amount of the sediment entering into the intake. With regard to the curve plotted by Hassanpour (2007), there is a linear relation between the intake ratio and the deviated sediment ratio for an intake ratio of less than $25 \%$.

Due to the fact that the intake ratio has a significant impact, compared to the Froude number, Hassanpour did not conduct the exper-

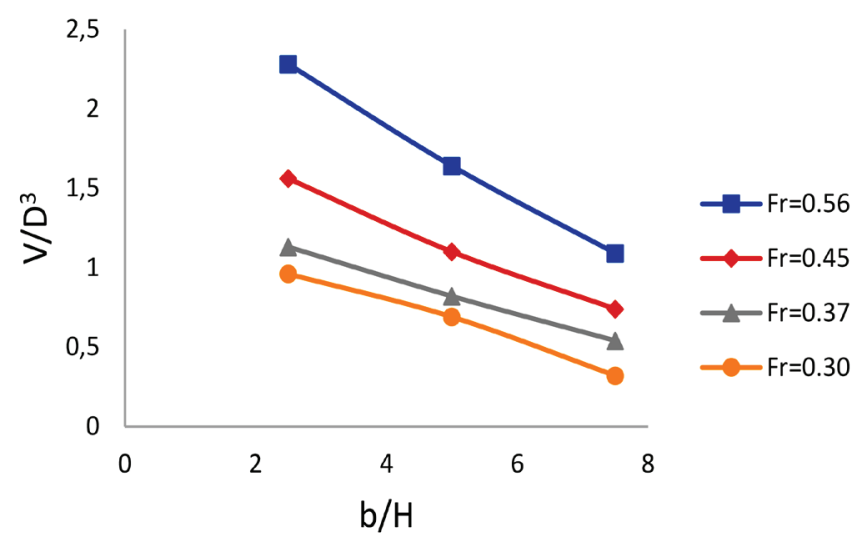

Fig. 5 Variation in $\frac{V}{D^{3}}$ with $\frac{b}{H}$ for different Froude numbers 


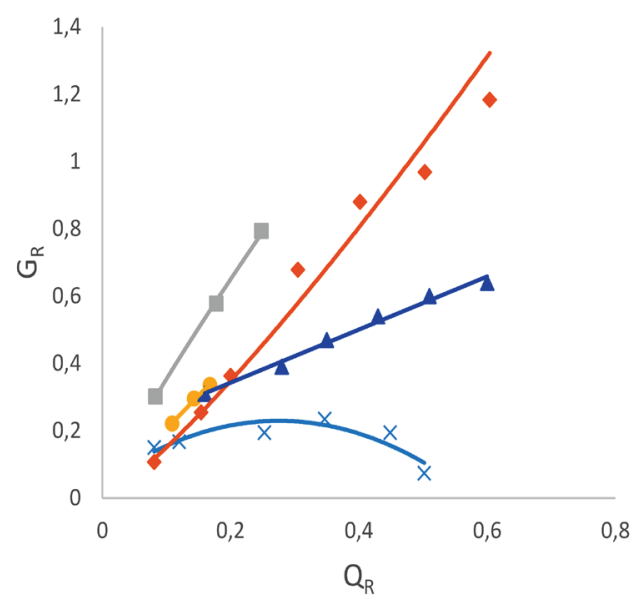

XBarkdoll(1999)

$\rightarrow$ Raudkivi(1993)

Hasanpour(2007)

- Moradinejad(2017)

$\Delta$ Present study

Fig. 6 Comparison of the results obtained for the ratio of the deviated sediment to the intake $\left(G_{R}\right)$ and the intake ratio $\left(Q_{R}\right)$ between the previous studies and present research, in the absence of a sediment control structure

iments for a single Froude number, but he focused on a range of 0.4 to 0.6 for the Froude number. Moradinejad (2017) assumed that the value of varies $Q_{R}$ between 0.1 to 0.2 and that an increase $Q_{R}$ in leads an increase in the ratio of the deviated sediment to the intake. He showed that a $14 \%$ increase in a stream's Froude number causes an increase in the ratio of the inlet sediment ratio to the intake up to $118 \%$. The present study demonstrated that an increase in the intake ratio $\left(Q_{R}\right)$ leads to an increase in the deviated sediment ratio to the intake $\left(G_{R}\right)$. The $\mathrm{G}_{\mathrm{R}}=\mathrm{V} / \mathrm{V}_{\text {canal }}$ relation yields the $G_{R}$ value, where $V_{\text {Canal }}$ denotes the sediment volume trapped in the end section of the main channel, and $\mathrm{V}$ refers to the accumulated sediment volume in the lateral intake. After measuring these volumes, the required calculations were carried out, and the associated curve was plotted. It is obvious that the findings and results of the present paper are in line with those of previous studies. Tab. 8 summarizes the governing equations of the previous studies.

The validation and comparison of the results for the present study were accomplished based on the experimental data and governing equations of the previous research, and the result are depicted in Fig. 7.

With regard to Fig. 7, the computational relation yields an RMSE equal to 0.2579 , based on the equation obtained by Barkdoll, while it yields an RMSE equal to 0.2083 based on the equation presented by Raudkivi. Moreover, the computational relation yields an RMSE

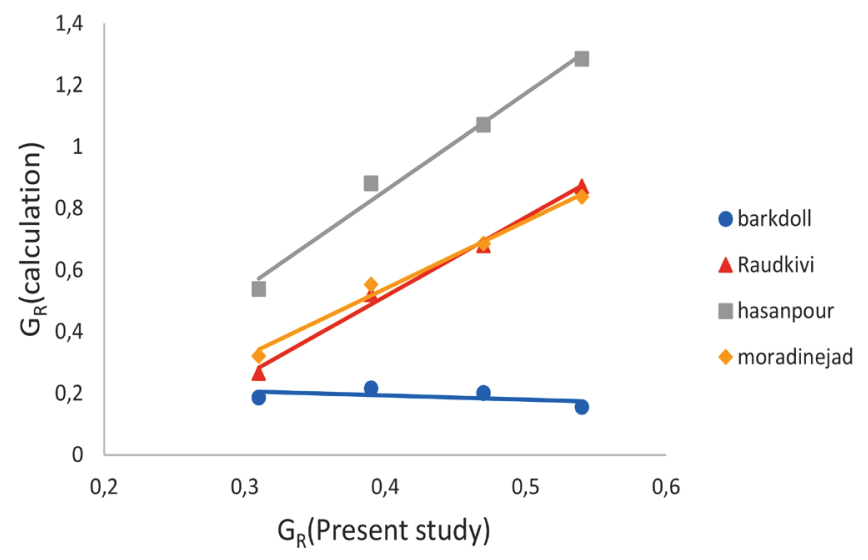

Fig. 7 Relation of the computational $G_{R}$ based on the governing equations of other scholars with the observational $G_{R}$ of the present paper
Tab. 5 Statistical information for the relation between $G_{R}$ and $Q_{R}$ based on previous studies

\begin{tabular}{|c|c|c|c|c|}
\hline Row & Scholar & Relation & $\boldsymbol{R}^{\mathbf{2}}$ & RMSE \\
\hline 1 & Barkdoll & $G_{R}=-2.4 Q_{R}^{2}+1.3 Q_{R}+0.04$ & 0.73 & 0.0290 \\
\hline 2 & Raudkivi & $G_{R}=2.4 Q_{R}^{1.2}$ & 0.98 & 0.0750 \\
\hline 3 & Hasanpour & $G_{R}=2.7 Q_{R}^{0.88}$ & 0.99 & 0.0077 \\
\hline 4 & Moradinejad & $G_{R}=1.9 Q_{R}^{0.97}$ & 0.99 & 0.0046 \\
\hline 5 & Present study & $G_{R}=0.86 Q_{R}^{0.57}$ & 0.98 & 0.0130 \\
\hline
\end{tabular}

equal to 0.5499, based on Hassanpour's equation, and it yields an RMSE equal to 0.2013 based on Moradinjead's equation. Therefore, the relations of the present paper are close to the relation presented by Raudkivi and Moradinejad.

\section{CONCLUSION}

In the present study, the variations of the distance of two the skimming walls from each other, the impact of the angle of the second branch of the parallel skimming wall structure relative to the direction of the stream in the main channel, and its role in the control of the inlet sediment to the lateral intake were studied. The results are presented as follows:

1) An increase in leads to an increase in the inlet sediment to the intake.

2) An increase in the Froude number of the stream of the main channel leads to an increase in the volume of the inlet sediment to the intake.

3 ) In the case of the presence of parallel skimming walls with distances of , and , the amount of the inlet sediment to the intake will be decreased on average by up to $58 \%, 70 \%$ and $86 \%$, respectively.

4) The presence of parallel skimming walls with a distance of from each other exhibits a desirable performance in controlling the volume of the inlet sediment, compared with the other cases.

5) In the presence of parallel skimming walls with an angle of, parallel to the direction of the stream within the main channel, the amount of the inlet sediment to the intake is reduced on average up to $69 \%$. In the presence of parallel skimming walls with angles of, the amount of the volume of the inlet sediment to the intake is reduced on average up to $41 \%$, while in the presence of parallel skimming walls with angles of , the amount of the inlet sediment to the intake is reduced on average up to $26 \%$.

6) The presence of parallel skimming walls with angles of relative to the other angles exhibits a desirable performance in controlling the inlet sediment to the intake.

7) The variations in the distance of the skimming walls from each other have a great impact on controlling the sediment, compared to the angle of the second branch of the walls.

8) The parallel skimming walls reduce the bed load of the sediment inlet of the main channel to the intake, while there will be an increase in the turbulence around the wall due to the collision with the stream at the bottom for high intake rates, which will result in the elevation of sediments from the bottom and their entry into the intake.

9) By making a comparison between the results of the present article and those of Rezabandloo (2017), Moradinejad et al. (2017), and Barkdoll et al. (1999), it can be inferred that the presence of parallel skimming walls with a distance of and a $0^{\circ}$ angle can lead to a reduction in inlet sediment to the lateral intake up to $86 \%$, which is in line with the findings of the preceding studies. 


\section{REFERENCES}

Abbasi, A.A. - Nejad-yazdi, M.M. (2014) The impact of sill and submerged vanes on sediment laden flow at lateral intake. Journal of Irrigation and Water Engineering, 16, pp. 106-117.

Atarzadeh, A. - Ayyoubzadeh, S. A. - Ghodsian, M. - Salehi-Neishabouri, A. (2014) Experimental Study of the Effect of Sill, Spur Dike and Submerged Vanes on Sediment Control and Bed Topography at Lateral Intakes. Modares Civil Eng. J. (M.C.E.J). 14(2), pp. 27 - 38 (In Persian).

Barkdoll, B. D. - Hagen, B. L. - Odgaard, A. J. (1995) Sediment exclusion at hydropower intakes using submerged vanes. Proceedings of Waterpower. ASCE, 1(1), pp. 892-908.

Barkdoll, B. D. - Ettema, R. - Thou, J. (1997) Sediment Control at Riverside Water Intakes. Proc. of the International Joint Power Generation Conference, Denver, CO, U.S.A., pp. 227-232.

Barkdoll, D. - Ettema, R. - Odgaard. A.J. (1999) Sediment control at lateral diversions: limits and enhancement to vane use. Journal of Hydraulic Engineering, 125(8).

Ghohari, S. - Ayyoubzadeh, S. A. - Ghodsian, M. - Salehi-Neishabouri, A. (2009) The Impact of Spur Dike and Submerged Vanes on Sediment Control at Lateral Intake. J. Water Soil Conserv, 16(2), pp. 35-59 (in Persian)

Hashid, M. - Hussain, A. - Ahmad, Z. (2015) Discharge Characteristics of Lateral Circular Intakes in Open Channel Flow. Flow Measurement and Instrumentation 46, part A, pp. 87 - 92.

Hassanpour, F. (2007) Performance Evaluation of Lateral Intakes in the Presence of Compound Submerged Vanes and Sill. Doctoral Dissertation, Tarbiat Modares University, Tehran, Iran.

Herreero, A. - Bateman, A. - Medina, V. (2015) Water Flow and Sediment Transport in a 90 Degree Channel Diversion: an Experimental Study. Journal of Hydraulic Research, 53(2), pp. 253-263.

Jafari-Mianaei, S. - Ayyoubzadeh, S. A. (2014) Experimental Investigation of the Effect of Inclined Main Channel Wall on the Amount of Delivered Sediment into the Lateral Intake With / Without Submerged Vanes. Iranian Journal of Irrigation \& Drainage, 4(7), pp. 521-534.

Khanjani, M. J. - Barani, G. A. - Rahmanian M. R. - Sajedi, M. (1999) Investigation of Submerged Vanes Array for Sediment Control at Intake Using a Physical Model. JCME, 18(2), pp. 179-189

Moradinejad, A. - Haghiabi, A. H. - Saneie, M. - Yonesi, H. (2017) Investigating the Effect of Skimming Wall on Controlling the Sediment Entrance at Lateral Intakes. Water Science \& Technology, Water Supply, 17(4), pp. 1121-1132.
Nakato, T. - Odgen, F. L. (1998) Sediment Control at Water Intakes along Sand Bed Rivers. Journal of Hydraulic Engineering, ASCE, 116(1), pp. 119-128.

Nakato, T. - Kennedy, J. F. - Bauerly, D. (1990) Pump - station Intake - shoaling control with submerged vanes. Journal of Hydraulic Engineering, ASCE, 116(1), pp. 119-128.

Neary, V. S. - Odgaard, A. J. (1993) Three-dimensional flow structure at open channel diversions. J. Hydr. Eng., ASCE, 119(11), pp. 1224-1230.

Odgaard, A. J. - Wang, Y. (1991) Sediment management with submerged vanes I. theory. Hydraulic Engineering, 117 (3), pp. 267283.

Ramamurthy, A. S. - Junying, Q. - Diep, V. (2007) Numerical and Experimental Study of Dividing Open - Channel Flows. J. Hydraul. Eng-ASCE, 133(10), pp. 1135-1144.

Raudkivi, A. J. (1993) Sedimentation, Exclusion and Removal of Sediment from Diverted Water, IAHR, Hydraulic Structures, Design Manual, pp. 63-87.

Rezabandloo, M. (2017) Experimental Investigation of Application of Skimming Wall for Controlling the Inlet Sediment to Intake of River, MSc Thesis, Faculty of Engineering, University of Science and Culture, Tehran, Iran.

Salemnia, A. - Shafaei-Bajestan, M. (2011) Investigation on the Effect of Submerged Vanes on the Amount of Sediment Entrance of Trapezoidal Channel into the Lateral Intake by Changing the Discharge Diversion Ratio. Proceedings of the $10^{\text {th }}$ Iranian Hydraulic Conference, University of Guilan, Rasht, Iran (In Persian).

Tabrizi, H. - Haghi Abi, A. H. - Sanei, M. - Younesi, H. A. (2017) Evaluation of spur dike effect on sediment and flow hydraulic of side intakes located on channel bends. Watershed Engineering and Management, 9(3), pp. 346-359.

Younesi, H. A. - Omid, M. H. - Kashefipour, M. (2005) Investigating the effect of longitudinal arrangement of submerged vanes in a direct channel on the bed topography, relative increase of drainage efficiency and reduction of sedimentation in the span of gravity intakes, The Science Journal of Agriculture (SJA), 27, pp. 137-150. 